\title{
ESTOMATITIS AFTOSA RECURRENTE: REPORTE DE UN CASO
}

\section{RECURRENT APHTHOUS STOMATITIS: A CASE REPORT}

\section{TÍTULO CORTO: ESTOMATITIS AFTOSA RECURRENTE}

\section{Xiomara Serpa-Romero¹, Paula Guarín-Rodríguez ${ }^{2}$}

Recibido en junio 12 de 2015

Aceptado en octubre 08 de 2015

\section{RESUMEN}

La estomatitis aftosa recurrente es una alteración de la mucosa oral asociada en algunos casos a la depresión del sistema inmunológico, el cual condiciona la respuesta tisular a nivel del epitelio, desencadenando el cuadro clínico repetitivo de ulceras pequeñas y medianas (3-5 mm), las cuales presentan fondo necrótico y bordes eritematosos de una duración no mayor a 15 días. El cuadro se vuelve recidivante, sintomático, comprometiendo la salud del paciente, quien consulta nuevamente con iguales características en cavidad oral. La literatura asocia el proceso con cambios hormonales, traumatismo, ingesta prolongada de medicamentos, y estrés. Se presenta un caso clínico en Santa Marta, en el Centro de Implantología y Rehabilitación Oral: paciente femenina de 53 años,quien acude al servicio de estomatología por presentar múltiples aftas orales que dificultan la deglución, marcada sialorrea y estado febril. De acuerdo al interrogatorio y al examen clínico se asocia con un proceso reactivo inflamatorio producido por la ingesta de medicamentos para tratar un proceso infeccioso o viral, al cual se le da el diagnóstico presuntivo de eritema medicamentoso. Se suspende toda ingesta de medicamentos y se ordenan exámenes complementarios de anticuerpos antinucleares.

Palabras clave: ulcera aftosa; inflamación; mucosa necrótica; recurrentes

\section{ABSTRACT}

Recurrent aphthosus stomatitis is an alteration of the oral mucosa in some cases associated with depression of the immune system that affects the tissue response at the level of the epithelium, triggering repetitive clinical picture of small and medium ulcers $(3-5 \mathrm{~mm}$ ) which necrotic presented erythematous background and lasting no more than 15 days. The picture becomes recurrent, symptomatic, compromising the health of the patient who consults again with the same characteristics in oral cavity. The literature associates the process with hormonal changes, trauma, prolonged intake of medications, and stress. A case of female patient 53 , who attends the service of dentistry to present multiple oral thrush that hard to swallow, drooling and feverish marked presents in Santa Marta, at the Center for Implantology and Oral Rehabilitation. According to the interrogation and clinical examination it is associated with a reactive inflammatory process caused by the intake of drugs to treat infectious or viral process, which is given the presumptive diagnosis of erythema drug. Any medication intake was suspended and additional tests are ordered antinuclear antibodies.

Keywords: ulcer disease; inflammation; necrotic mucosa; recurrent

1. Odontóloga, Especialista en Estomatología y Cirugía Oral. Docente, Universidad del Magdalena, Colombia. Correo: xiomaraserpa@gmail.com 2. Estudiante de odontología, Universidad del Magdalena, Colombia. Correo: paulag4495@gmail.com 


\section{INTRODUCCIÓN}

$\mathrm{L}$ a estomatitis aftosa recidivante o recurrente (EAR) Les una condición que se observa con frecuencia por los odontólogos en la práctica clínica. Estas ulceraciones pueden ser indicativas de enfermedades sistémicas subyacentes que van desde la deficiencia de algunas vitaminashasta compromiso inmunitario. El conocimiento de estas correlaciones ayuda al odontólogo a realizar el diagnóstico de condiciones potencialmente graves ${ }^{1}$.

Para el diagnóstico adecuado de dicha enfermedad es pertinente ejecutar un análisis clínico y un interrogatorio, además pruebas de laboratorio específicas para diagnosticarla ${ }^{2}$. La afección se clasifica como menor, mayor y herpetiforme sobre la base del tamaño, forma y el número de las úlceras. Los ataques pueden ser precipitados por traumatismo local, estrés, ingesta de alimentos, medicamentos, cambios hormonales y deficiencias de vitaminas ${ }^{3}$.

El estrés es uno de los factores desencadenantes más relacionados con la aparición de la EAR. Un estudio realizado por Sánchez et al. " "concluyó que el 90,3\% de los pacientes afectados por la EAR estaban sometidos a niveles de estrés, por lo que se comprobó la existencia de una asociación estadísticamente significativa entre estos desórdenes psicológicos y la enfermedad”. Igualmente, se ha señalado que el sexo femenino tiene una mayor prevalencia de esta enfermedad. Lópezet al. ${ }^{5}$, realizaron un estudio acerca de las características de la estomatitis aftosa recurrente, encontrando más afectado al sexo femenino, con un porcentaje del 58.5 del total de pacientes.

En el tratamiento primario de la EAR se utilizan agentes antiinflamatorios tópicos, sin embargo la literatura reconoce que el tratamiento más eficaz es la aplicación de corticoides tópicos, en forma de gel o crema ${ }^{6}$. El uso tópico de corticoides potentes mezclados con adherentes mucosos es efectivo a pesar del tiempo de contacto limitado con la mucosa; una película de hidroxipropilcelulosa (orabase) puede proteger la úlcera existente y proporcionar alivio del dolor. En los enfermos con sintomatologías que no se apaciguan con la primera fase del procedimiento o dichos síntomas tienden a justificar un método de tratamiento más severo, la prednisona debe ser tenida en cuenta, gracias a que es un agente antiinflamatorio e inmunodepresor que suele emplearse en combinación con geles tópico y enjuagues ${ }^{7}$. No existe una terapia curativa para prevenir la recurrencia de las úlceras y todas las modalidades de tratamiento disponibles, sólo pueden reducir la frecuencia o la gravedad de las lesiones ${ }^{3}$.

\section{CASO CLÍNICO}

Paciente femenino, 53 años de edad, refiere que hace 9 meses presenta lesiones ulcerativas en mucosa oral y pilares amigdalinos. Fue tratada inicialmente por el servicio de odontología general, quien ordenó tratamiento con antimicóticos y antibióticos simultáneamente. La paciente acude al servicio de estomatología debido a que presenta múltiples aftas orales que dificultan la deglución, con marcada sialorrea y estado febril. De acuerdo al interrogatorio y al examen clínico se sugiere inicialmente que es un proceso reactivo inflamatorio producido por la ingesta de medicamentos para atacar un proceso infeccioso o viral que fue tratado por el servicio médico y odontológico; en este momento, la impresión clínica es de eritema medicamentoso. Posteriormente, se ordenan exámenes complementarios de anticuerpos antinucleares.

Se suspende toda ingesta de antibióticos, antimicóticos y analgésicos, por cuanto llevaba un proceso de más de 15 días sin presentar mejoría. Se instaura como tratamiento único el uso de corticoides vía oral $(20 \mathrm{mg} /$ día durante 20 días el cual debe ingerirse a las $5 \mathrm{am}$; a partir del día 15 , reducir a $10 \mathrm{mg} /$ día y finalizar en el día 20 con $5 \mathrm{mg}$ ) y local, aplicando en mucosa oral $5 \mathrm{mg}$ de prednisolona diluido en $5 \mathrm{ml}$ de hidróxido de aluminio y $3 \mathrm{ml}$ de xilocaína gel, 15 minutos antes de la ingesta de alimentos. Pasados 4 días se empieza a observar disminución de la cantidad de aftas orales, mejorando su estado sistémico general. A los 20 días de finalizado el esquema instaurado, la paciente manifiesta mejoría total, tanto en sus mucosas como en su estado sistémico.

El reporte de los exámenes paraclínicos ordenados para anticuerpos antinucleares, con el fin de determinar enfermedades autoinmunes, fue negativo. Pasados 30 días aproximadamente de haber terminado el esquema instaurado, la paciente manifiesta nuevamente el inicio de lesiones aftosas dolorosas de menor diámetro en cara ventral de lengua y piso de boca (Figura 1), por lo cual se instaura un segundo esquema de corticoides sistémicos y en orabase en iguales concentraciones respecto al primer esquema con el fin de controlar la recidiva. Se observa a los pocos días mejoría con resolución total de las lesiones (Figuras 2 y 3 ). 


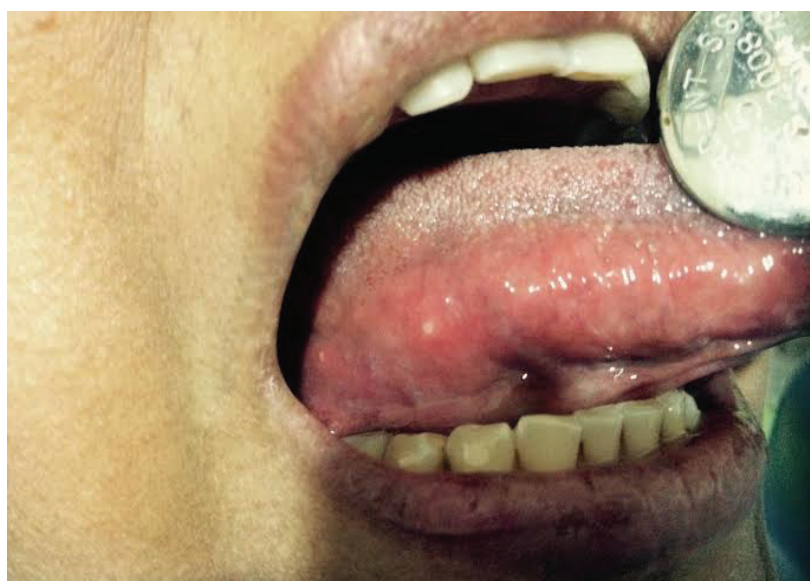

Figura 1. Ulcera aftosa de 3 días de evolución localizada en borde lateral de lengua, $3 \mathrm{~mm}$ de diámetro, rodeada por halo eritematoso. Fuente: elaboración propia.

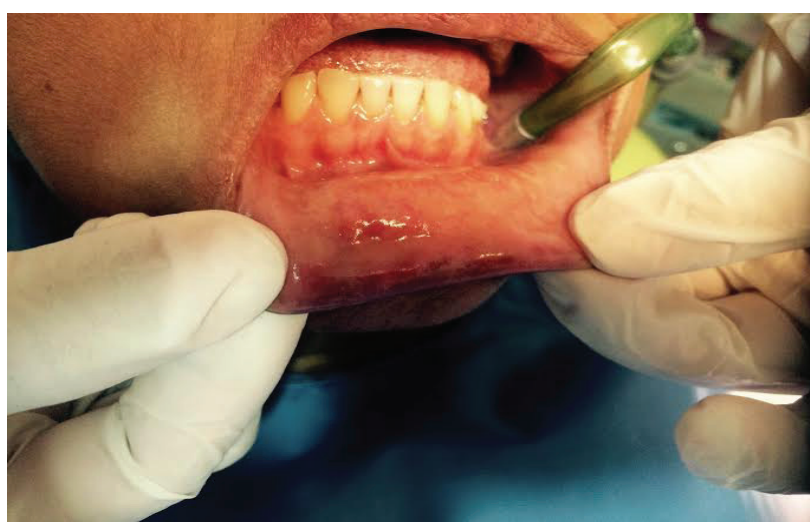

Figura 2. Proceso de resolución de una lesión en mucosa de labio inferior. 15 días de evolución. Fuente: elaboración propia

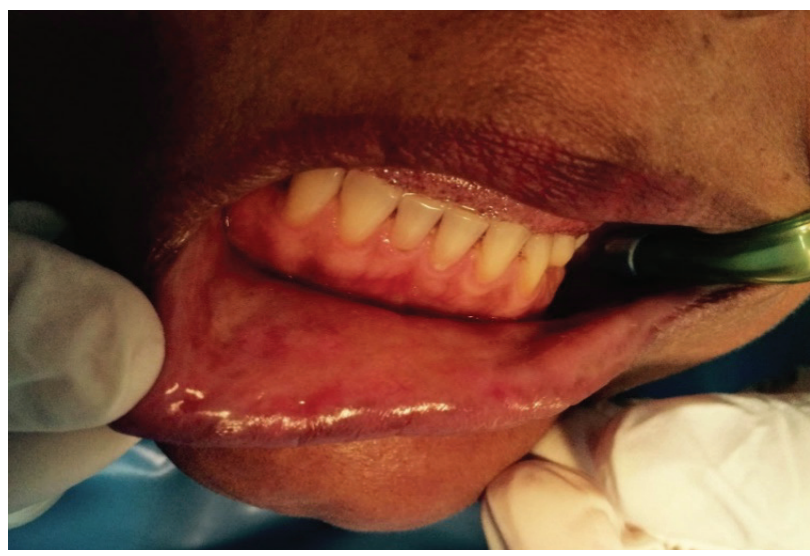

Figura 3. Imagen aumentada del proceso de resolución de la lesión aftosa en labio inferior.
En la actualidad la paciente presenta lesiones esporádicas en cavidad oral de menor tamaño, por lo cual se solicita interconsulta con medicina interna y endocrinología, para que se analicen otros factores sistémicos que predisponen a la recidiva; y/o instaurar un esquema con corticoides más amplio y a su vez se controlen los efectos secundarios de los mismos.

\section{DISCUSIÓN}

La EAR se considera la más común de todas las lesiones de la mucosa oral ${ }^{7,4}$ y afecta alrededor del $20 \%$ de la población ${ }^{8}$. La EAR es un proceso inflamatorio doloroso que aparece en la cavidad oral con una marcada predisposición a los procesos recidivantes posiblemente asociados a factores hormonales, psicológicos, carenciales (déficit de ácido fólico o vitaminas B12) ${ }^{9-11}$, y alimenticios como alergias a sustancias como las nueces, chocolate y gluten ${ }^{9}$.Cura en pocos días, semanas o meses, en dependencia de los factores de riesgo que la desencadenaron; y las lesiones se repiten periódicamente ${ }^{10}$.

La probabilidad de que las ulceras aftosas se relacionen con un defecto inmunitario es grande, y por lo tanto, un tratamiento racional debe incluir fármacos con capacidad para manipular o regular la reacción inmunitaria. En la actualidad, los corticosteroides brindan en esa categoría la mejor probabilidad de contener la enfermedad ${ }^{5,12}$. El uso de los corticoides controla significativamente la recidiva del proceso, sin embargo deben ordenarse con cierta cautela para evitar efectos secundarios a largo plazo. Se sugiere además del uso del medicamento, controlar los posibles factores desencadenantes, lo cual marcaría un equilibrio que disminuiría la recidiva. Cuando esto no se logra se sugiere realizar interconsultas médicas con los servicios de medicina interna, endocrinología y psicología, para mejorar la calidad de vida del paciente. No obstante, en muchos de los casos la respuesta es satisfactoria al esquema instaurado y la recidiva se presenta a largo plazo.

En cuanto a la prevalencia de la EAR, podemos señalar que es una enfermedad muy común; que casi no se reporta debido a la poca importancia que le da el campo de la medicina general, asociándolo generalmente a otras patologías que también se manifiestan como ulceras en la cavidad oral. Por esta razón se debe tener presente como característica específica de esta enfermedad, la aparición de ulceras con diámetro menor a $4 \mathrm{~mm}$ únicamente en mucosa oral y su capacidad repetitiva es la que lleva al paciente a consultar con el profesional. Cuando el paciente acude a la consulta médica presentando estas lesiones 
recurrentes de tipo aftosa, el direccionamiento no se está haciendo al servicio estomatológico indicado; de tal forma que muchos de los casos son tratados de manera inexacta, tal como el de este reporte de caso, en el cual se estaba medicando a la paciente con antibióticos y antimicóticos, especulando un proceso infeccioso.

Algunos de los casos de EAR, ingresan por el servicio odontológico general; donde el profesional está en la capacidad de identificar los factores predisponentes en su paciente y tratar de eliminarlos; aliviando las molestias locales con técnicas odontológicas como eliminar cúspides traumáticas, prótesis desadaptadas, obturaciones desbordantes, entre otras. Si con estas alternativas de tratamiento no se logra quitar la sintomatología recurrente se ordenan exámenes complementarios para descartar enfermedades autoinmunes y si el reporte continúa negativo, podemos asegurar que estamos frente a un proceso de EAR y tratarlo según los esquemas establecidos tanto sistémica como localmente.

\section{DECLARACIÓN SOBRE CONFLICTO DE INTERESES}

Los autores no reportan conflictos a declarar relacionados con la investigación.

\section{REFERENCIAS BIBLIOGRÁFICAS}

1. Casiglia JM. Recurrent aphthous stomatitis: Etiology, diagnosis, and treatment. Gen Dent.[internet] 2002;50:157-66. [consultado 2015 mayo 29] Disponible en: http://www.ncbi.nlm.nih.gov/pubmed/12004710

2. Castelnaux M, Jiménez A, Navarro J, González Y, Rodríguez Z. Estomatitis aftosa recurrente según factores locales y generales. MEDISAN[Internet]. 2013; 17(9): 5027-5034. [citado 2015 Junio 28]. Disponible en: http://scielo.sld.cu/scielo.php?script = sci_arttext\& pid $=$ S1029-30192013000900010

3. Natah SS, Konttinen YT, Enattah NS, Ashammakhi N, Shrakey KA, Häyrinen-Immonen R. Recurrent aphthous ulcers today: a review of the growing knowledge. Int J Oral MaxillofacSurg.[internet] 2004;33:221-34. [consultado 2015 julio 2] Disponible en: http://www. ncbi.nlm.nih.gov/pubmed/15287304

4. Sánchez Z, Martínez I, Gato I. El estrés como factor de riesgo de la estomatitis aftosa recurrente. Rev.Med. Electrón. [Internet]. 2011; 33(1):39-44. [consultado 2015 Junio 28]. Disponible en: http://scielo.sld.cu/scielo. php $?$ script $=$ sci_arttext \&pid $=$ S1684- 18242011000100006

5. López A, Ilisástigui Z, Pérez A. Características de la estomatitis aftosa recurrente en pacientes de la Clínica Estomatológica Docente Hermanos Gómez: Municipio 10 de Octubre. Revhabanciencméd[Internet]. 2009;8(4) [consultado 2015 Junio 28]. Disponible en: http://scielo.sld.cu/scielo.php?pid = S1729519X2009000400013\&script $=$ sci_arttext\&tlng $=$ pt

6. Sapp P, Eversole L, Wysocki G. Patología oral y Maxilofacial contemporánea. Segunda edición.Madrid: Editorial ELSEVIER MOSBY; 2005

7. Salinas Y, Millán R, León J. Estomatitis aftosa recidivante: Conducta odontológica. Acta odontol. venez[Internet]. 2008; 46(2): 209-218. [consultado 2015 Agosto 27]. Disponible en:http://www.scielo. org.ve/scielo.php? script $=$ sci_arttext\&pid $=$ S0001 $63652008000200021 \& \operatorname{lng}=$ es\&nrm $=$ iso\&tlng $=$ es

8. Figueroa K. Estomatitis aftosa recurrente. Rev. MedBasadrina [internet]. 2013; 7(2): 52. [consultado 2015 julio 2] Disponible en: http://www.unjbg.edu. pe/revistas/pdf/20140430-revistamV7-2.pdf $\#$ page $=54$

9. Regezi J, Sciubba J. Patología Bucal. Correlaciones clinicopatológicas. Tercera edición. México: Editorial McGraw- Hill Interamericana; 2000.

10. Troya E, Martínez J, Padilla E, Iglesias N, Ramos A.La estomatitis aftosa recurrente y las situaciones de estrés como factor de riesgo. Rev. Med. Electron. [internet] 2014; 36(6): 799-812. [consultado 2015 Agosto 27]. Disponible en:http://scielo.sld.cu/scielo.php?script $=$ sci_ arttext\&pid $=$ S1684-18242014000600001\&lang $=p t$

11. Pacho J, Piñol F.Estomatitis aftosa recurrente: Actualización.Rev. Cubana Estomatol[Internet]. 2005;42(1). [consultado 2015 Agosto 26]. Disponible en:http://scielo.sld.cu/scielo.php?script = sci_arttext\& pid $=$ S0034-75072005000100006

12. Espitia-Nieto S, Gómez-Romero M, Vargas-Pérez J. Láser de diodo; opción terapéutica para liquen plano erosivo resistente a corticoterapia: reporte de caso. Duazary. 2016 enero; 13 (1): 47 - 51 